\title{
Um jogo de construção para o aprendizado colaborativo de Glicólise e Gliconeogênese
}

\section{A Constructive Game to introduce the collaborative learning of Glycolysis and Gluconeogenesis}

Felipe Sales de Oliveira, Caroline Dutra Lacerda ${ }^{1}$, Patrícia Santos de Oliveira ${ }^{1}$, Ana Amália Coelho ${ }^{1}$, M. Lucia Bianconi ${ }^{1 *}$

${ }^{1}$ Programa de Educação, Gestão e Difusão em Biociências do Instituto de Bioquímica Médica, Universidade Federal do Rio de Janeiro, Rio de Janeiro-RJ.

*e-mail: bianconi@biogmed.ufrj.br

\begin{abstract}
Resumo
O jogo "Glicólise \& Gliconeogênese" foi desenvolvido para auxiliar alunos do curso de Odontologia da Universidade Federal do Rio de Janeiro no aprendizado colaborativo dessas vias metabólicas. O jogo inicia com 11 cartas contendo apenas a fórmula estrutural dos intermediários da glicólise, as quais devem ser colocadas numa sequência correta de modificações estruturais, desde a glicose até o piruvato. Após completarem a via corretamente, os alunos recebem 10 cartas das enzimas, as quais indicam a reversibilidade (ou não) da reação, o valor de energia livre e os ativadores e/ou inibidores, quando for o caso. Após responderem questões de fixação do conteúdo, por meio de observações da via metabólica montada, os alunos recebem cinco novas cartas que permitem a substituição daquelas necessárias para transformar a glicólise em gliconeogênese. A avaliação por 18 alunos sugere que o jogo é uma ótima estratégia de ensino de vias metabólicas podendo ser usado para outras vias além dessas que utilizamos.
\end{abstract}

Palavras-chave: jogo educativo, glicólise, gliconeogênese

\begin{abstract}
The game "Glicólise e Gliconeogênese" was developed to introduce the collaborative learning of metabolic pathways to Dental School students of the Universidade Federal do Rio de Janeiro. The game starts with 11 cards with the structural formula of the glycolysis intermediates that need to be placed in the correct sequence of structural changes from glucose to pyruvic acid. After that, the students get 10 enzyme cards that indicates the reversibility (or not) of the reaction, the free energy value and activators and/or inhibitors, if this is the case. After answering questions to consolidate the content through observations of the metabolic pathway, the students get five new cards that allow the substitution of the cards need to transform glycolysis in gluconeogenesis. The evaluation by 18 students suggests that the game is a great learning strategy of metabolic pathways that can be used to others than those showed here.
\end{abstract}

Keywords: educational game, glycolysis, gluconeogenesis 


\section{Ficha da atividade desenvolvida}

Título: Um Jogo de Construção para o Aprendizado Colaborativo de Glicólise e Gliconeogênese.

Público alvo: Alunos estudando a via glicolítica e a gliconeogênese.

Disciplinas relacionadas: Bioquímica.

Objetivos educacionais: Utilizar uma ferramenta lúdica e colaborativa para facilitar a aprendizagem do funcionamento da via glicolítica e da gliconeogênese.

Justificativa de uso: Os alunos têm dificuldade para entender as vias metabólicas e, geralmente, apenas decoram os nomes das enzimas e dos metabólitos para efeito de avaliação. O jogo "Glicólise e Gliconeogênese" visa facilitar a visualização do funcionamento dessas vias por meio das modificações nas fórmulas estruturais de seus intermediários, do tipo de reação que ocorre, bem como a sua regulação. Espera-se promover a compreensão dos fenômenos e, assim, a construção do raciocínio lógico sobre tais eventos.

Conteúdos trabalhados: Modificações estruturais, regulação e produtos formados na via glicolítica e na gliconeogênse. 


\section{Introdução}

A disciplina Bioquímica é ministrada no ciclo básico em diversos cursos de graduação, como, por exemplo, Medicina, Farmácia, Odontologia, Enfermagem, Biologia, Nutrição, entre outros. Geralmente, a Bioquímica é um pré-requisito para outras disciplinas e, portanto, falhas na aprendizagem dos conteúdos da mesma podem comprometer a formação do aluno ao longo do curso [1]. Porém, muitos estudantes, definem "Bioquímica" como sendo uma disciplina muito complexa, de conteúdo extenso e abstrato, principalmente por apresentar uma extensa quantidade de estruturas químicas [2]. Da mesma forma, muitos professores têm dificuldade na escolha de estratégias que ajudem no processo de ensino-aprendizagem [3].

Além disso, o processo de avaliação utilizado pelos professores nem sempre leva à construção do conhecimento [4], o que obriga o aluno a memorizar os conceitos, sem que haja uma aprendizagem significativa dos mesmos. No caso das vias metabólicas, por exemplo, notamos que os alunos memorizam os nomes dos intermediários, mas não os reconhecem quando suas fórmulas estruturais Ihes são apresentadas.

Atividades lúdicas têm sido propostas a fim de diminuir as dificuldades e despertar um maior interesse dos alunos em interagir com a disciplina. Estas devem ser escolhidas pelo professor, de acordo com o perfil da turma. Segundo Lara [5], os jogos educativos podem ser classificados como sendo de "competição", "construção", "treinamento", "aprofundamento" ou "estratégicos". Um ponto importante observado por Lara [5] é a necessidade de que o jogo educativo não dependa do fator sorte, ou seja, que o vencedor seja aquele que descobrir as melhores estratégias. Além disso, é importante que o jogo permita "a construção de algumas abstrações que, muitas vezes, são apenas transmitidas pelo professor e memorizadas sem uma real compreensão pelo aluno prejudicando, assim, o aprendizado" [5].

Há relatos bem sucedidos da utilização de atividades lúdicas para o ensino de Bioquímica. O uso de mangás (histórias em quadrinhos japonesas) com conteúdo de Bioquímica aumentou o interesse dos alunos pela disciplina, auxiliando no processo de ensino-aprendizagem [6]. Azevedo e colaboradores [7] mostraram que o aprendizado dos alunos que estudaram o Ciclo de Krebs por meio de um jogo em duas versões, uma no formato de tabuleiro convencional (versão em papel) e outra, virtual (software), foi semelhante. A diferença apontada pelos autores entre os grupos foi relacionada ao nível de satisfação dos alunos que, aparentemente, preferem o formato virtual do jogo. $O$ jogo "Perfil - Biomoléculas" tem como objetivo inter-relacionar características estruturais, 
classificação e função de carboidratos, lipídios e proteínas, sendo que a elaboração do material envolveu os alunos, que se sentiram motivados [8]. Os autores relataram que o jogo incentivou o raciocínio e a articulação dos conceitos químicos e biológicos [8]. A avaliação do jogo de tabuleiro Bioquim ${ }^{4 x}$, o qual visa rever conceitos de Bioquímica por meio de diferentes dinâmicas, foi bastante positiva, já que os alunos consideram que o mesmo contribuiu para o aprendizado da disciplina e que, apesar de ter apresentado certa dificuldade, foi dinâmico [9].

Além de facilitar o aprendizado, as atividades lúdicas em sala de aula podem contribuir para estreitar os laços entre professor e aluno, a partir de uma maior aceitação/empatia pela disciplina e pelo professor [10].

Jogos educativos também contribuem para o aprendizado colaborativo, um estilo de ensino descrito como sendo importante para aumentar o interesse entre os participantes e promover mudanças de atitude como, por exemplo, o de incentivar o pensamento crítico [11].

O jogo apresentado neste artigo foi criado como uma tentativa de auxiliar na compreensão das vias metabólicas, aumentando a familiaridade com as reações, os intermediários e a regulação das mesmas, de forma lúdica. É um jogo classificado como de "construção", pois, de acordo com Lara [5], é aquele que traz, ao aluno,

[...] um assunto desconhecido fazendo com que, através da manipulação [...] de perguntas e respostas, ele sinta a necessidade [...] de um novo conhecimento, para resolver determinada situação-problema proposta pelo jogo. E, na procura desse novo conhecimento ele tenha a oportunidade de buscar por si mesmo uma nova alternativa para sua resolução.

Essa definição foi criada para jogos de matemática, mas se adapta perfeitamente ao jogo proposto para o aprendizado das vias metabólicas apresentado neste artigo.

\section{Objetivo}

O objetivo do jogo é fazer com que o aluno reconheça as transformações que ocorrem nos intermediários da glicólise e da gliconeogênese a partir da observação das fórmulas estruturais dos mesmos, bem como as enzimas envolvidas. 


\section{Material e Métodos}

\subsection{Material}

O jogo é composto por doze cartas de intermediários da glicólise e gliconeogênese, catorze cartas contendo as enzimas e uma folha com as regras. As cartas dos intermediários contêm apenas a fórmula estrutural dos mesmos. As cartas das enzimas indicam se a reação é reversível ou irreversível, o valor de $\square$ G das reações e a indicação dos inibidores e/ou ativadores, caso existam. As fórmulas estruturais dos intermediários foram desenhadas com o programa ChemDraw ${ }^{\circledR}$ Standard 12.0 (PerkinElmer) e as cartas foram criadas no programa livre Paint.Net 4.0.4 (Softonic). Após impressão em cores, as cartas foram plastificadas, para aumentar sua resistência e durabilidade. As cartas não contêm os nomes dos compostos intermediários, os quais são apresentados aos alunos após a finalização do jogo. Duas delas apresentam as informações "INÍCIO" (glicose) e "FIM" (piruvato). A Figura 1 traz exemplos de cartas, e o conjunto completo está disponível em http://www.biogmed.ufrj.br/docentes/textos/novo-metodo-ludico-para-oensino-de-bioquimica.
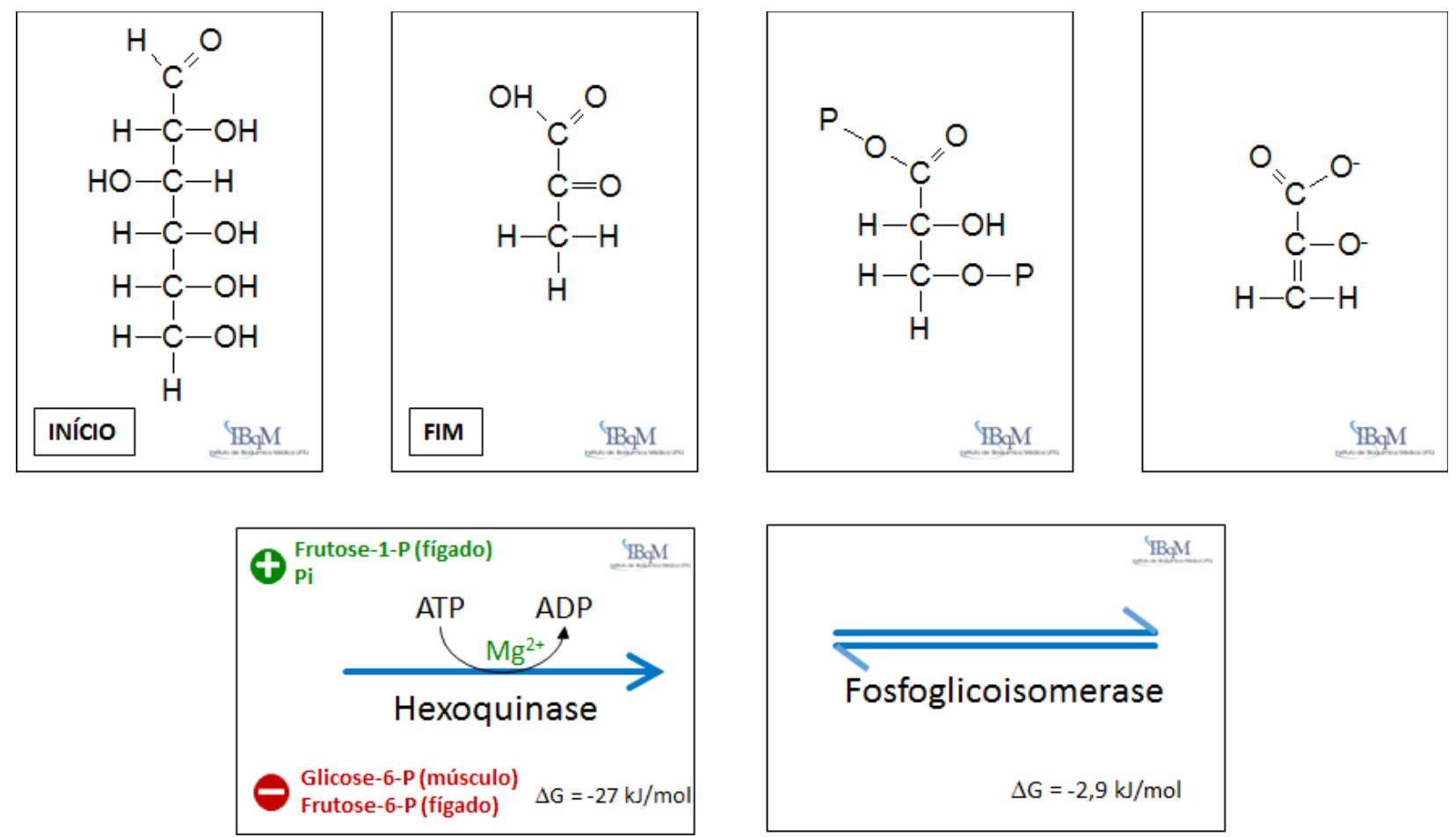

Figura 1. Exemplo de cartas contendo as fórmulas estruturais de quatro compostos intermediários da glicólise e de duas reações com o valor do $\square$ G, uma irreversível, contendo as informações sobre sua regulação, e outra, reversível. O conjunto completo das cartas está disponível em: http://www.biogmed.ufrj.br/docentes/textos/novo-metodo-ludico-para-o-ensino-de-bioquimica/ 


\subsection{Preparo Inicial}

Os alunos devem ser divididos em grupos de dois a cinco participantes. Cada grupo deve ficar em torno de uma bancada ou mesa, de modo que todos possam acompanhar o desenvolvimento do raciocínio necessário para a montagem das vias metabólicas. Cada grupo deve receber os dois conjuntos de cartas (estruturas e reações), separadamente, como explicado a seguir, além da folha com as regras do jogo e uma tabela com a classificação das enzimas.

\subsection{Regras}

O jogo é dividido em quatro etapas:

(1) construção da via glicolítica utilizando apenas as cartas das fórmulas estruturais;

(2) inclusão das cartas contendo as reações/enzimas;

(3) respostas a um questionário de fixação de conteúdo, respondido pela observação da via (enzimas, reações e energia livre); e

(4) construção da gliconeogênese pela substituição das cartas necessárias.

$\mathrm{Na}$ primeira etapa, utilizando apenas as cartas contendo os intermediários da via glicolítica, os alunos devem desvendar o caminho correto de modificações das estruturas químicas partindo da carta indicada como "INÍCIO" (Glicose) até chegar à carta indicada como "FIM" (Piruvato). Sugerimos aos alunos que separem os compostos de seis carbonos dos compostos de três carbonos. Nas regras, há uma sugestão de organização das cartas (Figura 2) e a indicação para que organizem, inicialmente, as cartas de seis carbonos.

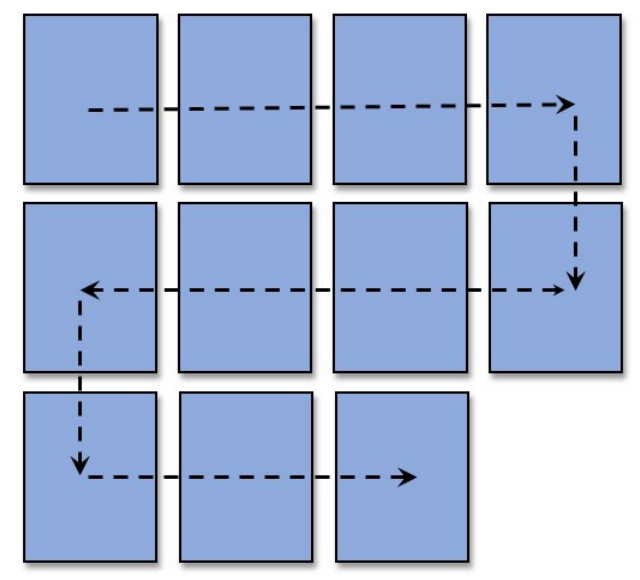

Figura 2. Sugestão de organização das cartas contida nas regras do jogo. 
Além das regras, são apresentadas duas "dicas": (1) "Atenção aos grupos químicos"; e (2) "Procure notar se o composto seguinte foi fosforilado (ganhou um grupo fosfato) ou desfosforilado (perdeu um grupo fosfato)". É, também, explicado que o "P" na estrutura dos compostos fosforilados representa o grupo fosfato, proveniente da ligação de um grupo fosfito $\left(\mathrm{PO}_{3}^{2-}\right)$ ao oxigênio do composto intermediário.

Na sequência das regras, é indicado que o último composto de seis carbonos alinhado na via metabólica será clivado em dois compostos que devem ser identificados antes de continuar a montagem da via. Nesse momento, é importante a intervenção do professor para checar se o raciocínio foi correto. É dada uma terceira dica: "Na via glicolítica, ambos estão em equilíbrio e apenas um deles continua a ser modificado!".

Na segunda etapa, os alunos devem sinalizar para o professor quando finalizarem a organização das cartas que são, então, conferidas para que possam dar continuidade ao jogo. Estando na ordem correta, o professor dá as cartas das enzimas que também devem ser colocadas na ordem correta. Ao longo da aplicação, vimos ser necessário fornecer uma tabela contendo a classificação das enzimas que resume o tipo de reação catalisada pelas mesmas para consulta. Nesse momento, é explicado que entre duas cartas "estruturas" sempre haverá uma carta "reações". Ao final, o grupo deve acusar o término do jogo e solicitar ao professor que verifique se as cartas foram colocadas de forma correta.

Na terceira etapa, com o objetivo de fixar o conteúdo, os alunos respondem a um questionário com 12 questões, sendo que as últimas se referem à síntese de Glicose. Perguntamos se é possível sintetizar Glicose pela reversão da glicolise e pedimos para que sugiram como ocorre a síntese de glicose a partir de piruvato. Percebendo que existem reações irreversíveis e que haveria necessidade de outras enzimas para completar a nova via, os alunos recebem mais quatro cartas, uma delas com a fórmula do oxalacetato e outras três com as enzimas que substituem aquelas que catalisam as reações irreversíveis. Dessa forma, iniciam a quarta etapa, de construção da gliconeogênese.

Para fixar esse conteúdo, os alunos completam uma tabela preenchida após a glicólise que contém a lista dos ativadores e inibidores da via, com aqueles que regulam a gliconeogênese. Assim, os alunos percebem como as duas vias estão relacionadas em termos das necessidades energéticas do indivíduo. Ou seja, inibidores de uma via podem ser ativadores da outra e vice-versa. 


\subsection{Avaliação do Jogo}

Dezoito alunos da disciplina de Bioquímica, oriundos do primeiro período do curso de Odontologia da Universidade Federal do Rio de Janeiro, responderam voluntariamente e de forma anônima a um questionário contendo seis questões relativas à caracterização da amostra, sete questões fechadas contendo afirmativas para serem analisadas de acordo com uma escala de Likert [12], para verificar a opinião dos alunos em relação ao jogo, além de uma questão aberta para comentários gerais. A escala de Likert adotada variava da seguinte forma:

1: Discordo Fortemente

2: Discordo

3: Não Tenho Opinião

4: Concordo

5: Concordo Fortemente

Foram calculadas as médias e desvios padrões das médias das respostas pelo programa Origin (MicroCal, Llc.), apresentadas em uma tabela. A distribuição das respostas entre os itens, apresentada em gráficos, foi calculada como percentual de respostas em relação ao total de alunos participantes.

A questão aberta, para comentários gerais, era facultativa ("se quiser, faça comentários, críticas e sugestões”).

\subsection{Caracterização da amostra}

Dos dezoito alunos participantes, um era do sexo masculino e dezessete do sexo feminino, com idades entre 17 e 26 anos. Dezesseis alunos não tinham cursado a disciplina de Bioquímica anteriormente, um aluno era repetente do mesmo curso e o outro, havia cursado Bioquímica antes de ingressar em Odontologia, no curso de Farmácia em outra Universidade.

\section{Resultados}

\subsection{Avaliação do jogo}

Antes da aplicação em uma sala de aula, fez-se um pré-teste do jogo, suas regras e até mesmo do questionário de avaliação. Para isso, convidamos alguns alunos veteranos que seguiram todos os passos da mesma forma que seria apresentado aos novos alunos. Porém, no pré-teste testaram-se as cartas relativas à via glicolítica, apenas, 
sendo que a ideia de incluir a gliconeogênese surgiu nessa etapa, devido a alguns comentários durante a aplicação do jogo.

Tivemos a participação de oito alunas do segundo e do terceiro período de Odontologia nesta Universidade. Todas avaliaram o jogo de forma muito positiva e foram unânimes em dizer que o jogo era mais interessante que a aula teórica, sendo que uma delas respondeu à questão aberta, para comentários gerais, com o seguinte depoimento:

O jogo é uma ótima forma de aprender a via glicolítica sem necessitar decorá-la, uma vez que ele fornece os nomes das reações, a fórmula dos compostos e dicas exigindo dos alunos raciocínio e conhecimento básico de química adquirido no ensino médio. Ao jogar, tive uma visão totalmente diferente daquela projetada num slide em sala de aula, consegui ver as mudanças que ocorrem nas moléculas e só assim pude completar a via. Sendo assim, o jogo torna a via muito mais interessante e vemos sentido nas mudanças de um composto para o outro.

A avaliação do jogo da Glicólise e Gliconeogênese se deu pela aplicação de um questionário contendo sete afirmativas que foram respondidas com uma escala de Likert [12] com cinco itens, variando de 1 (discordo fortemente) a 5 (concordo fortemente). Dessa forma, ao serem calculadas as médias das respostas, aquelas com valores menores que 3 indicavam que os alunos tendem a discordar da afirmativa, enquanto aquelas com valores maiores que 3 indicavam uma tendência a concordar com a afirmativa. O resultado da avaliação se encontra na Tabela 1.

Tabela 1. Questões avaliadas pelos alunos e os seus respectivos resultados com as médias e DP.

\begin{tabular}{lc}
\hline \multicolumn{1}{c}{ Afirmativas } & $\begin{array}{c}\text { Média } \\
( \pm \text { desvio padrão })\end{array}$ \\
\hline I. As regras estão claras & $4,2 \pm 0,5$ \\
II. Foi possível compreender como ocorrem as modificações nas moléculas & $4,1 \pm 0,6$ \\
III. Consegui finalizar as vias estudadas através do jogo & $4,4 \pm 1,0$ \\
IV. Há muita necessidade de intervenção do professor & $3,2 \pm 1,2$ \\
V. Preferia aprender a via glicolítica em uma aula tradicional (slides) & $2,1 \pm 1,0$ \\
VI. Gosto de jogos & $4,2 \pm 1,0$ \\
VII. Foi interessante interagir com colegas na construção da via glicolítica & $4,6 \pm 0,6$ \\
\hline
\end{tabular}

Foi possível verificar que a maioria dos alunos concorda $(66,7 \%)$ ou concorda fortemente $(27,8 \%)$ que as regras estão claras, mas, aparentemente, muitos necessitam da intervenção do professor (Figura 3). Nesse caso, não foi possível definir uma opinião devido à grande distribuição das respostas (Figura 3). Ainda assim, 77,8\% dos alunos concorda que foi possível compreender como ocorrem as modificações nas moléculas, sendo que a maioria conseguiu finalizar as vias estudadas com o jogo.

Apesar das respostas bastante positivas, quando analisamos a questão que se refere à forma preferencial de aprender a via glicolítica, pudemos verificar que 22,2\% não sabe opinar sobre o assunto. $\mathrm{Na}$ verdade, se considerarmos que esses alunos nunca 
tiveram uma aula teórica (tradicional, com o uso de slides) sobre o assunto, essa é uma questão difícil de ser respondida.
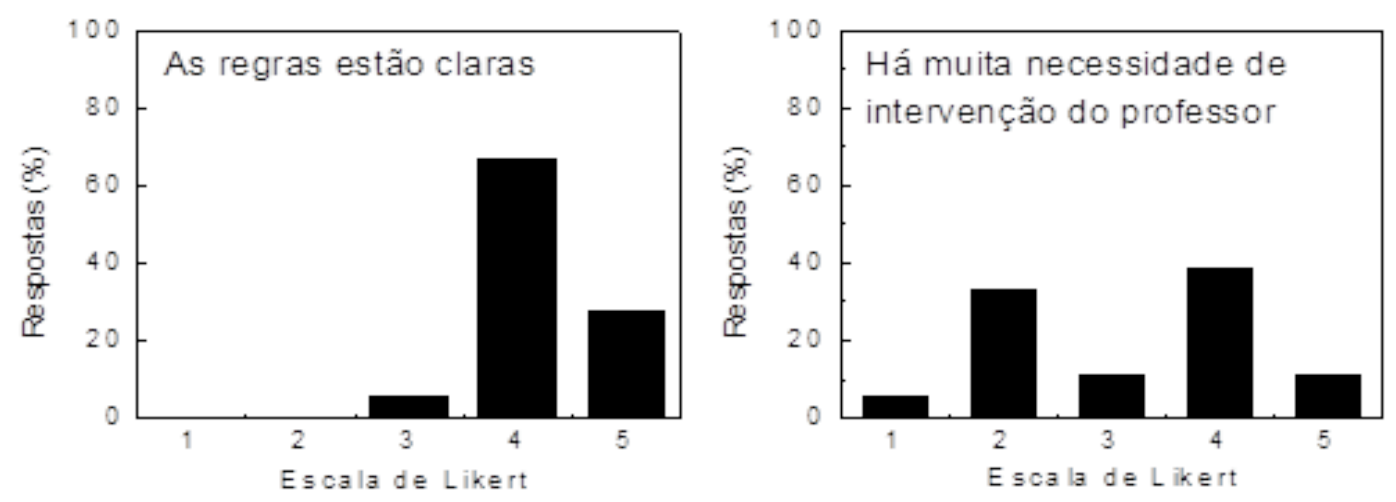

Figura 3. Distribuição das respostas dos alunos de acordo com a escala de Likert, onde 1 representa "discordo fortemente" e 5 representa "concordo fortemente" para as afirmativas I e IV da avaliação (ver Tabela 1).
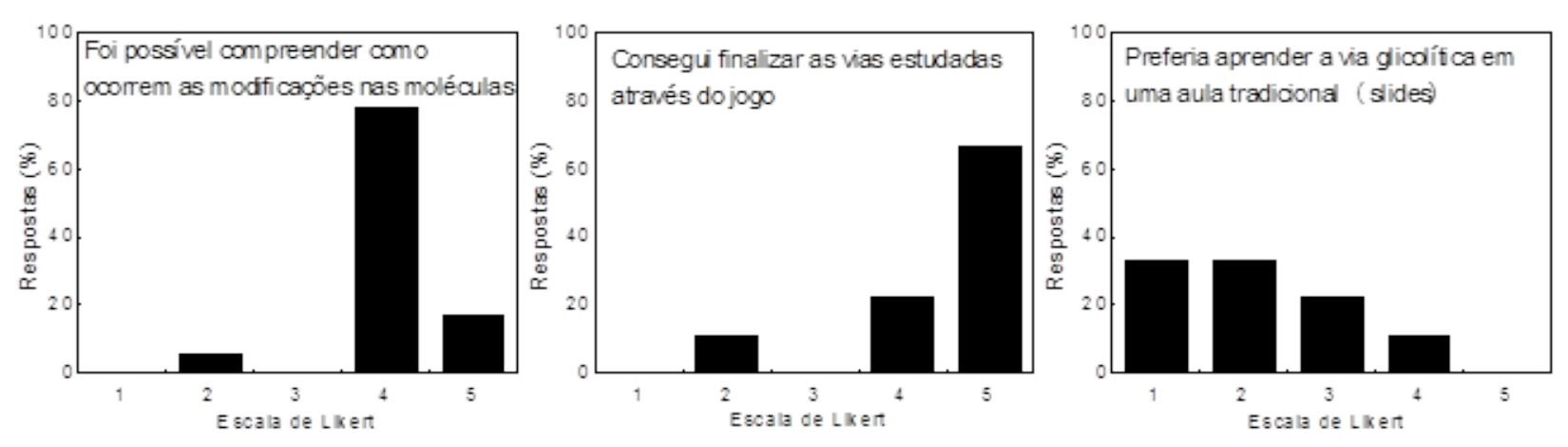

Figura 4. Distribuição das respostas dos alunos, de acordo com a escala de Likert, onde 1 representa "discordo fortemente" e 5 representa "concordo fortemente" para as afirmativas II, III e V da avaliação (ver Tabela 1).

Os alunos gostam de jogos e consideram interessante interagir com colegas na construção da glicólise (Figura 5).
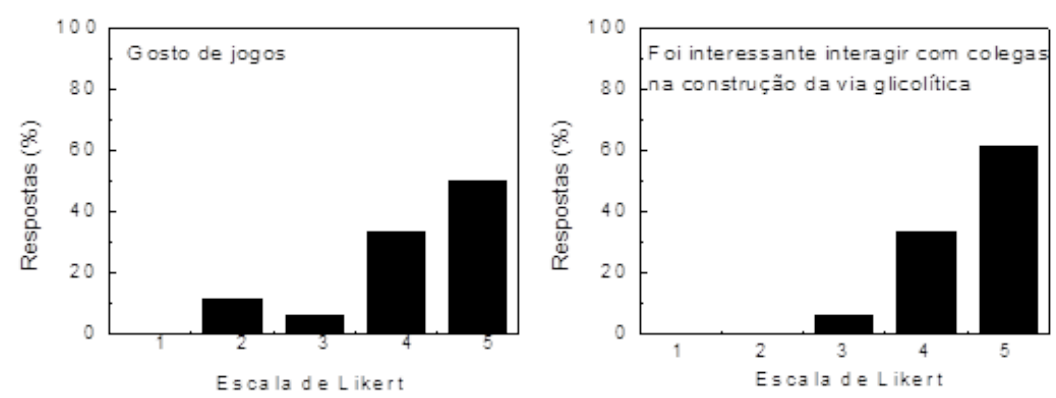

Figura 5. Distribuição das respostas dos alunos, de acordo com a escala de Likert onde 1 representa "discordo fortemente" e 5 representa "concordo fortemente" para as afirmativas VI e VII da avaliação (ver Tabela 1).

No que se refere à questão aberta, somente três alunos teceram comentários, reafirmando a aprovação dos mesmos com relação ao jogo, como destacado abaixo: 
"Com esse jogo o aprendizado fica muito mais divertido e interessante, se fosse somente slides não seria a mesma coisa pois depois de muito tempo de aula o aluno começa a se dispersar. Se fosse possível fazer jogos com outras partes da matéria seria mais interessante, porém sei que o período é curto e não teria tempo para fazer sempre isso." Aluno A

"No começo eu não havia entendido, mas ficou mas fácil de entender a matéria." Aluno B

"Gostei da técnica usada." Aluno C

\section{Conclusão}

A partir dos resultados descritos, observam-se indícios que o jogo "Glicólise \& Gliconeogênese" apresenta um grande potencial didático, podendo servir como uma importante ferramenta para professores de Bioquímica que procuram diversificar suas aulas. A aluna veterana que participou do pré-teste e deu o depoimento citado nos resultados, também comentou que a Bioquímica é "uma matéria de difícil compreensão e não muito aceita pelos alunos se tornando um entrave no desenvolvimento acadêmico dos mesmos." No caso das vias metabólicas, por tratar-se de um tema reconhecidamente difícil, onde os alunos comumente recorrem a simples memorização das etapas das vias metabólicas sem o completo entendimento do processo, o jogo se configura com um recurso alternativo que pode ajudar na resolução desse problema.

Mesmo tendo sido aplicado em um único curso de graduação, acreditamos que o seu potencial didático pode se estender para os demais cursos que apresentam a disciplina de Bioquímica em sua grade curricular, tendo em vista os bons resultados obtidos nas duas avaliações (pré-teste e final), por se tratar de uma dinâmica simples e de baixo investimento financeiro. 


\section{Referências}

[1] Schoenmaker F. Análise das dificuldades na disciplina de Bioquímica diagnosticadas por um Plantão por um Plantão de Dúvidas on line. Universidade de São Paulo, 2009.

[2] Vargas LHM. A Bioquímica e a Aprendizagem Baseada em Problemas. Rev Ensino Bioquímica 2001; 1:15-9.

[3] Wood EJ. Biochemistry is a difficult subject for both student and teacher. Biochem Educ 1990; 18:170-2.

[4] Barbosa MRLS, Martins APR. Avaliação: Uma Prática Constante no Processo de Ensino e Aprendizagem. Rev Da Católica 2011; 3. Acesso em 20 de Fevereiro de 2015. Disponível em:

http://catolicaonline.com.br/revistadacatolica2/artigosv3n5/artigo27.pdf

[5] Lara ICM. Jogando com a matemática de 5a a 8a série. Rêspel. São Paulo: 2003.

[6] Nagata R. Learning biochemistry through manga - Helping students learn and remember, and making lectures more exciting. Biochem Educ 1999; 27:200-3.

[7] Azevedo AMP, Lazzarotto GB, Timm MI, Zaro MA. Relato de uma experiência com o uso do Diagrama Metabólico Dinâmico Virtual do Ciclo de Krebs. Novas Tecnol Na Educ 2004; 2:1-9.

[8] Perazzo P, Barbosa DS, Gadelha TS, Alberto C, Gadelha DA, Persuhn C. Perfil - Biomoléculas. Rev Ensino Bioquímica 2014; 12:24-33.

[9] Farkuh L, Pereira-leite C. Bioquim4x: um jogo didático para rever conceitos de bioquímica. Rev Ensino Bioquímica 2014; 12:37-54.

[10] Randi MAF. Criação, aplicação e avaliação de aulas com jogos cooperativos do tipo RPG para o ensino de biologia celular. Universidade Estadual de Campinas, 2011. 
[11] Gokhale AA. Collaborative learning enhances critical thinking. J Technol Educ 1995; 7:22-30.

[12] Likert R. A technique for the measurement of attitudes. Arch Psychol $1932 ; 140: 1-55$.

\section{Agradecimentos}

Aos alunos do curso de Odontologia da Universidade Federal do Rio de Janeiro que participaram da avaliação deste jogo. 